\title{
Relevance of the interplay between amyloid and tau for cognitive impairment in early Alzheimer's disease
}

Maarten Timmers ${ }^{\mathrm{a}, \mathrm{b}, *}$, Ina Tesseur ${ }^{\mathrm{a}}$, Jennifer Bogert ${ }^{\mathrm{c}}$, Henrik Zetterberg ${ }^{\mathrm{d}, \mathrm{e}, \mathrm{f}, \mathrm{g}}$, Kaj Blennow ${ }^{\mathrm{d}, \mathrm{e}}$, Anne Börjesson-Hanson ${ }^{\mathrm{h}}$, Miquel Baquero ${ }^{\mathrm{i}}$, Mercè Boada $^{\mathrm{j}}$, Christopher Randolph $^{\mathrm{k}}$, Luc Tritsmans $^{\mathrm{a}}$, Luc Van Nueten ${ }^{\mathrm{a}}$, Sebastiaan Engelborghs ${ }^{\mathrm{b}, \mathrm{l}}$ Johannes Rolf Streffer ${ }^{\mathrm{a}, \mathrm{b}}$

${ }^{a}$ Janssen Research and Development, a division of Janssen Pharmaceutica N.V., Beerse, Belgium

b Reference Center for Biological Markers of Dementia (BIODEM), Institute Born-Bunge, University of Antwerp, Antwerp, Belgium

${ }^{\mathrm{c}}$ Janssen Research and Development LLC, Raritan, NJ, USA

${ }^{\mathrm{d}}$ Department of Psychiatry and Neurochemistry, Institute of Neuroscience and Physiology, the Sahlgrenska Academy at the University of Gothenburg, Mölndal, Sweden

${ }^{\mathrm{e}}$ Clinical Neurochemistery Laboratory, Sahlgrenska University Hospital, Mölndal, Sweden

${ }^{\mathrm{f}}$ Department of Neurodegenerative Disease, UCL Institute of Neurology, Queen Square, London, United Kingdom

g UK Dementia Research Institute at UCL, London, United Kingdom

${ }^{\text {h }}$ Sahlgrenska University Hospital, Mölndal, Sweden

${ }^{\text {i }}$ Hospital Universitari I Politecnic La Fe, Neurology Department, Valencia, Spain;

${ }^{\mathrm{j}}$ Research Center and Memory Clinic. Fundació ACE. Institut Català de Neurociències Aplicades, Universitat Internacional de Catalunya-Barcelona, Spain

${ }^{\mathrm{k}}$ MedAvante-ProPhase, Hamilton, NJ, USA

${ }^{1}$ Department of Neurology and Memory Clinic, Hospital Network Antwerp (ZNA) Middelheim and Hoge Beuken, 2020 Antwerp, Belgium

\section{*Corresponding author:}

Maarten Timmers 
Janssen Research and Development,

A division of Janssen Pharmaceutica N.V.

Beerse, Belgium

Tel: +3214608122

Email: mtimmer3@its.jnj.com

Previous presentation: A part of the data hase been presented at the The $13^{\text {th }}$ international

Conference on Alzheimer's and Parkinson's Diseases and Related Neurological Disorders,

AD/PD ${ }^{\text {TM }}$ 2017, 29 March - 2 April 2017, Vienna, Austria.

Journal Requirements

1. Regular manuscripts should be no longer that $\mathbf{1 0}$ printed journal pages ( $\mathbf{3 0}$ doubledspaced pages, including references, figures and tables) and should include only the most essential figures and tables

2. Divide your article into clearly defined and numbered sections. Subsections should be numbered 1.1 (then $1.1 .1,1.1 .2, \ldots), 1.2$, etc. use this numbering also for internal crossreferencing

3. State the objectives of the work and provide an adequate background, avoiding a detailed literature survey or a summary of the results.

4. Avoid extensive citations and discussion of published literature.

5. A concise and factual abstract is required. The abstract, not to exceed 170 words, should state briefly the purpose of the research, the principal results and major conclusions.

6. Highlights are mandatory for this journal. They consist of a short collection of bullet points that convey the core findings of the article and should be submitted in a separate editable file in the online submission system.

7. Tables can be placed either next to the relevant text in the article, or on separate page(s) at the end.

8. To foster transparency, we encourage you to state the availability of your data in your submission. 


\begin{abstract}
Amyloid $\beta(\mathrm{A} \beta)$ and tau are key hallmark features of Alzheimer's disease (AD) neuropathology. The interplay of $\mathrm{A} \beta$ and tau for cognitive impairment in early $\mathrm{AD}$ was examined with crosssectional analysis, measured by cerebrospinal fluid (CSF) biomarkers (A $\beta_{1-42}$, total tau [t-tau] and phosphorylated tau $\left.\left[\mathrm{p}-\operatorname{tau}_{181 \mathrm{P}}\right]\right)$, and on cognitive performance by the repeatable battery for assessment of neuropsychological status (RBANS). Participants $(n=246)$ included cognitively normal $\left(\mathrm{A} \beta^{-}\right)$, mild cognitively impaired $(\mathrm{A} \beta-)$, preclinical $\mathrm{AD}(\mathrm{A} \beta+)$, and prodromal $\mathrm{AD}$ $(\mathrm{A} \beta+)$. Overall, cognitive impairment (RBANS Total Scale score) had a moderate negative correlation to t-tau $(n=246 ; r=-0.434 ; p<0.001)$ and $p$-tau $181 \mathrm{P}(r=-0.389 ; \mathrm{p}<0.001)$. When classified by $A \beta$ status, this correlation to t-tau was applicable only in $A \beta+$ participants $(n=139$; $\mathrm{r}=-0.451, \mathrm{p}<0.001)$ but not $\mathrm{A} \beta-$ participants $(\mathrm{n}=107 ; \mathrm{r}=0.137, \mathrm{p}=0.16)$, with identical findings for $p$-tau. Both tau $(p<0.0001)$ and interaction of $A \beta_{1-42}$ with tau $(p=0.006)$ affected RBANS, but not $\mathrm{A} \beta_{1-42}$ alone. Cognitive/memory performance correlated well with CSF tau levels across early stages of $\mathrm{AD}$, although the correlation is $\mathrm{A} \beta$ dependent.
\end{abstract}

Keywords: Alzheimer's disease, amyloid, tau, interaction, RBANS, cognition 


\section{Introduction}

The hallmark pathological changes of Alzheimer's disease (AD), amyloid- $\beta(A \beta)$ plaques and tau neurofibrillary tangles (NFT) are known to start accumulating years before the onset of clinical symptoms (Dubois et al., 2016; Villemagne et al., 2013), with a putative sequence of A $\beta$ events preceding tau. With the molecular definition of the disease (Jack et al., 2018), the progressing clinical disorder of $\mathrm{AD}$ is considered a continuum with a seamless sequence of events from healthy elderly individuals with positive biomarker signature and impairments gradually increasing over time to progress from milder stages of cognitive deficits to functional impairment and dementia (Aisen et al., 2017; Jack et al., 2013). This interpetation of AD was enabled by advances in cerebrospinal fluid (CSF) and imaging biomarkers such as $\mathrm{A} \beta$ and tau to move from a clinically defined late stage disease to a biological definition of a disease process that starts many years before onset of clinical symptoms. These research avances have resulted in a new set of criteria for $\mathrm{AD}$ to define the earliest stages in the $\mathrm{AD}$ continuum, i.e., cognitively normal individuals with an abnormal AD biomarker pattern, being preclinical AD (Dubois et al., 2014; Knopman and Caselli, 2012; Vos et al., 2013).

The amyloid cascade hypothesis brings forward the deposition of $\mathrm{A} \beta$ as a result of increased production and/or decreased clearance of $\mathrm{A} \beta$ from the central nervous system, as the initial pathological trigger in the disease continuum, interacting with the microtubule-binding protein tau, forming NFT leading to widespread neuronal degeneration and dysfunction, cognitive decline and dementia (Karran et al., 2011). Genetic evidence from rare familial forms of AD as well as mutations in amyloid- $\beta$ precursor protein (APP) and presenilins 1 and 2 genes support the

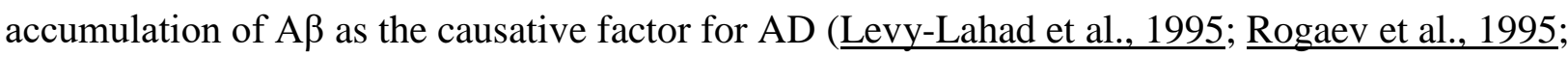
Sherrington et al., 1995). 
While genetic evidence points towards $A \beta$ as the initiator of pathology, the eventual clinical syndrome appears to be more closely related to the progression of the tau pathology. The rate of cognitive impairment in AD and neuronal loss however strongly correlate spatially and temporally with the total tau burden and NFT formation (Nelson et al., 2012; 2017). While A $\beta$ pathology spreads inwards starting from the cortex, progression of tauopathy in AD topographically disconnects and goes in the opposite direction (Braak et al., 2006). In animal models, both $\mathrm{A} \beta$ and tau have shown self-propagation capabilities (Jucker and Walker, 2011, 2013), but whether this occurs in humans is not known. Extracellular phospho-tau (p-tau) seeds are known to induce tauopathy in neurons, supporting the hypothesis that tauopathy can spread in a prion-like fashion between neurons, a cascade that could potentially be initiated or accelerated by A $\beta$ pathology (Goedert et al., 2017). Despite the prominent correlation of NFTs with cognitive impairment in $\mathrm{AD}$, mutations in tau are not causative for $\mathrm{AD}$ but may result in dementia, without an AD clinical or neuropathological phenotype (Hardy and Selkoe, 2002). Increasing preclinical evidence supports a possible interplay between $A \beta$ and tau, whereby $A \beta$ may exert its toxicity through tau by influencing or inducing the hyperphosphorylation, misfolding and secretion of tau (Musiek and Holtzman, 2015; Nisbet et al., 2015) and tau may further enhance $A \beta$ toxicity via a feedback loop. In addition, preclinical data demonstrates that tau is required for learning and memory deficits in the presence of $A \beta$ (Roberson et al., 2007). $\mathrm{A} \beta$ is being proposed as the trigger to $\mathrm{AD}$, which may induce the cascade of downstream events including tauopathy, and tau as the bullet, driving the neurodegeneration and cognitive deficits (Bloom, 2014). This potential interplay would further strengthen the interaction between both key hallmark features of the amyloid cascade hypothesis already at the start of the AD continuum, hypothesizing that the relation of CSF tau to cognitive performance is dependent on $\mathrm{A} \beta$ pathology as measured by CSF A $\beta$ levels. 
The interaction of $A \beta$ and tau, measured by means of CSF biomarkers $\left(A \beta_{1-42}\right.$, total tau [t-tau] and p-tau $181 \mathrm{P})$, on cognitive performance as a clinical marker in normal participants and those in the earliest stages of the AD continuum defined as preclinical and prodromal AD (pAD) was investigated.

\section{Methods}

\subsection{Study population}

Participants screened from two separate clinical trials in early Alzheimer's disease (Study 1: NCT01978548 (Timmers et al., 2018); Study 2: NCT02260674) were included in this study. Both studies were conducted in sites across Europe in Caucasian participants between December 2013 and June 2016.

\subsection{Study participants}

A total of 256 participants (Study 1: $n=112$; Study 2: $n=144$ ), aged 50 to 90 years inclusive, who completed a standardized 4-step screening process for either studies to assess their eligibility according to predefined inclusion and exclusion criteria (Supplemental fig S1), were included in this study (Timmers et al., 2018). Of the 256 participants who completed the screening process, a total of 10 participants were further excluded from final analysis, due to incorrect, incomplete or missing RBANS data recorded $(n=7)$, missing $p$-tau $181 \mathrm{P}$ data $(\mathrm{n}=1)$ or no CDR data $(\mathrm{n}=2)$ available, resulting in 246 evaluable participants.

Two paradigms were used to classify participants included $(n=246)$ as depicted in Supplemental Fig. S2.

\subsubsection{Biomarker CSF A $\beta_{1-42}$ and cognitive status (CDR).}

Participants were identified as "preclinical $A D$ " $(\mathrm{CDR}=0$ and $\mathrm{A} \beta<600 \mathrm{ng} / \mathrm{L}[\mathrm{A}+] \mathrm{n}=33)$, prodromal Alzheimer's disease (pAD; $C D R \geq 0.5$ but no dementia; $C D R=0.5[n=104]$ and 1.0 
$[\mathrm{n}=2]$, together with $\mathrm{A} \beta<600 \mathrm{ng} / \mathrm{L}[\mathrm{A}+], \mathrm{n}=106)$, "mild cognitive impairment" (MCI; CDR=0.5 and normal $A \beta$ levels $\left.\left[\mathrm{A}^{-}\right](\geq 600 \mathrm{ng} / \mathrm{L}), \mathrm{n}=38\right)$ or "control" (CDR=0 and normal $\mathrm{A} \beta$ levels $\left[\mathrm{A}^{-}\right]$, $n=69)$.

\subsubsection{Biomarker status alone independent of clinical stage; i.e., by $A \beta(A-/ A+)$ and tau $(T-/ T+)$}

status.

Participants were considered T+ if CSF t-tau and/or p-tau $181 \mathrm{P}$ were above the pre-defined cut-off (t-tau $>350 \mathrm{ng} / \mathrm{L} ; \mathrm{p}$-tau ${ }_{181 \mathrm{p}}$ levels $\left.>70 \mathrm{ng} / \mathrm{L}\right)$. All participants positive for $\mathrm{p}$-tau trip $_{1}$ were positive for t-tau given the strong correlation between both markers independent of $A \beta$ status $(A-: r=$ 0.95, $\mathrm{p}<0.001 ; \mathrm{A}+\mathrm{r}=0.95, \mathrm{p}<0.001$; Supplemental Fig. S3). Overall, $\mathrm{n}=70$ were A-/T-, $\mathrm{n}=37$ were $\mathrm{A}-/ \mathrm{T}+, \mathrm{n}=23$ were $\mathrm{A}+/ \mathrm{T}-$, and $\mathrm{n}=116$ were $\mathrm{A}+/ \mathrm{T}+$.

\subsection{Assessments}

\subsubsection{Mini-Mental State Examination}

The MMSE (Folstein et al., 1975) was used during screening as a tool to screen dementia.

\subsubsection{Clinical Dementia Rating Scale}

The Clinical Dementia Rating Scale (CDR), a semi-structured interview of patients and informants, was used to measure a patient's current dementia status (Morris et al., 1997). The CDR demonstrates good reliability (Burke et al., 1988) and has been validated against neuropathological findings (Berg et al., 1993).

\subsubsection{Repeatable Battery for the Assessment of Neuropsychological Status (RBANS)}

The RBANS ( (FORM A and FORM B) to explore test-retest reliability. For the purpose of this study, the first completion of the RBANS (either FORM A or B) was included in the analysis. 


\subsubsection{Collection and analysis of CSF $A \beta_{1-42}$, $p$-tau $181 p$ and $t$-tau Levels}

All participants had a baseline CSF sample $(12 \mathrm{~mL})$ collected during screening by single lumbar puncture between the L3 and L4 or L4 and L5 intervertebral space. CSF samples were collected in polypropylene tubes to avoid adsorbance of proteins to test tube walls. CSF samples were mixed to avoid possible gradient effects, aliquoted, frozen and stored at $-80^{\circ} \mathrm{C}$ immediately after collection. All samples analyzed in this study had at most 1 freeze-thaw cycle.

CSF samples were analyzed at one central lab (Sahlgrenska University hospital, Sweden) for $\mathrm{A} \beta_{1-42}$, phosphorylated tau at position threonine $181\left(\mathrm{p}-\mathrm{tau}_{181 \mathrm{P}}\right)$ and total tau $(\mathrm{t}-\mathrm{tau})$ concentrations using INNOTEST ${ }^{\circledR}$ Phospho-TAU $_{181}$, INNOTEST ${ }^{\circledR}$ hTAU Ag, and INNOTEST ${ }^{\circledR}$ $\beta$-AMYLOID $1-42$ (Fujirebio, Ghent, Belgium) (Palmqvist et al., 2014; Timmers et al., 2018), following stringent protocols for quality control of analyses. Diagnostic threshold CSF concentrations for $\mathrm{AD}$ versus normal control for $\mathrm{A} \beta_{1-42}\left(\mathrm{CSF} A \beta_{1-42}\right.$ levels below cut-off value of $600 \mathrm{ng} / \mathrm{L}$ ) were applied to the current sample set to assess the likelihood of having cerebral A $\beta$ plaque deposition (A+) (Palmqvist et al., 2014; Timmers et al., 2018). In addition, elevated CSF t-tau (>350 ng/L) and/or p-tau181p levels (>70 ng/L) respectively $(\mathrm{T}+)$ as set by the analysis lab at the start of Studies 1 and 2 were applied to the current sample set to assess the likelihood of having neuronal injury and/or cerebral tau pathology $(\mathrm{T}+)$.

\subsection{Statistical analyses}

Statistical analyses were performed using SAS Software version 9.4 (SAS Institute). For categorical data, group differences were analyzed using Fisher's Exact test. For numerical data when there were no clear departures from a normal distribution (age, height, weight, and BMI), balance across groups was evaluated with an F-test and pairwise group comparisons were analyzed by Student's t-test (equal variances) or Satterthwaite test (unequal variances). Nonparametric statistics ( $\underline{\text { Hollander, } 1999})$ were used for skewed or truncated data $\left(\mathrm{A} \beta_{1-42}, \mathrm{t}-\mathrm{tau}\right.$, 
p-tau 181 P, RBANS, and MMSE). Balance across groups was evaluated with a Kruskal-Wallis test. For pairwise comparisons, Hodges-Lehmann estimates for median differences between groups were calculated. Confidence intervals (CIs) and nominal p-values for the pairwise differences between groups were based on the Wilcoxon Rank Sum test. The choice of parametric versus nonparametric methods was driven by normality versus non-normality of data distributions. Spearman correlation coefficients were calculated to evaluate the strength of association between RBANS indexes and tau (t-tau and p-tau $181 \mathrm{P})$. Multiple linear regression models were employed to explore the relationship between cognition (RBANS) and biomarkers (A $\beta_{1-42}$, t-tau and the interaction of $A \beta_{1-42}$ with t-tau). Similar models using p-tau $181 \mathrm{P}$ instead of t-tau were analysed. Both t-tau and p-tau $181 \mathrm{P}$ were not included together in the same model due to colinearity. Ranktransformed values were used for RBANS and biomarker variables in multiple regression models because assumptions for normality in the model residuals were not met.

\section{Results}

\subsection{Demographic, biomarker and cognitive characteristics}

Two paradigms were used to classify participants as depicted in Supplemental Fig. S2, i.e., by $A \beta_{1-42}$ and cognitive status $(C D R)$ and by biomarker status alone indendent of clinical stage. i.e., by $A \beta_{1-42}$ and tau (T-/T+) status (see 2.2.1 and 2.2.2). For both classifications, the demographic, cognitive (RBANS, CDR, MMSE) and biomarker characteristics $\left(\mathrm{A} \beta_{1-42}, \mathrm{p}\right.$-tau tr1p $_{\mathrm{p}}, \mathrm{t}$-tau $)$ are summarized in Table 1A and Table 1B. The distribution of the overall population enrolled based on their A $\beta$ and tau biomarker profiles is shown in Supplemental Fig. S4 (A: A $\beta$ and p-tau $181 \mathrm{P}$; B: $\mathrm{A} \beta$ and t-tau). Gender distribution was equal across groups independent of classification used (by $A \beta_{1-42}$ and cognitive status or biomarker only). A tendency towards higher representation of male subjects in the $A+/ T-v s$ the $A+/ T+$ group was observed which was in line with earlier reports 
(Paquet et al., 2018). Participants classified as pAD and A+/T+ had lower weight and BMI and participants classified as $\mathrm{A}-/ \mathrm{T}-$ were younger.

\subsection{Prodromal $A D$, preclinical $A D$, control and MCI groups}

No differences in CSF $A \beta_{1-42}$ levels were observed amongst $\mathrm{A}+$ groups ( $\mathrm{pAD}$ vs preclinical $\mathrm{AD}$ ) or amongst $\mathrm{A}-$ groups (MCI vs control). Tau levels (t-tau; p-tau $181 \mathrm{P}$;median [range]) were significantly increased in both pAD (644.5 ng/L [161;1780]; $86.5 \mathrm{ng} / \mathrm{L}$ [29;197] vs control and MCI $\mathrm{p}<0.001)$ and preclinical AD (404 ng/L [118;1050] vs control $\mathrm{p}<0.05$, vs MCI $\mathrm{p}<0.01$; and $59 \mathrm{ng} / \mathrm{L}$ [23;128] vs control p<0.05, vs MCI p<0.01) compared with control (324 ng/L [152;742]; $50 \mathrm{ng} / \mathrm{L}$ [25;116]) and MCI groups (300 ng/L [100;661]; 46 ng/L [20;103]). No differences in CSF tau (t-tau or p-tau $181 \mathrm{P}$ ) levels were observed between the control and MCI group (Table 1A). The pAD group showed significantly increased tau levels compared with the preclinical AD group ( $\mathrm{p}<0.001$ for both t-tau and $\mathrm{p}$-tau $181 \mathrm{P})$ (Table $1 \mathrm{~A})$.

Overall, pAD participants presented with a lower (median [range] global MMSE score (26 [14;30], $\mathrm{p}<0.001)$, and a lower RBANS Total Scale score $(74$ [47;124], $\mathrm{p}<0.001$; Table 1A, Fig. 1A) and significant impairment on all RBANS index scores (Supplemental Table S1; $<<0.001$ ) compared with the control and preclinical AD groups, and for most of the RBANS index scores compared with the MCI group. The pAD participants showed highest impairment (lowest score) on the Delayed Memory Index followed by the Attention Index, Immediate Memory Index, Language Index and Visuospatial Index. The preclinical AD group showed a normal cognitive profile on the RBANS Total Scale and Index scores (Table 1A, Fig. 1A, Supplemental Table S1), while the MCI group had a significantly $(\mathrm{p}<0.001)$ lower RBANS Total Scale score (Table 1A; Fig. 1A) and index scores (Supplemental Table S1) compared with the preclinical AD and control group. The MCI group showed the highest impairment on the Attention Index, followed by Delayed Memory, Immediate Memory, Language, and Visuospatial Index. 


\section{3. $A-/ T-, A-/ T+, A+/ T-, A+/ T+$ groups}

High tau values (p-tau $181 \mathrm{P}$ and t-tau) were observed only in the A+ participants. Significantly $(\mathrm{p}<0.001)$ higher $\mathrm{t}-\mathrm{tau}$ and $\mathrm{p}$-tau $181 \mathrm{P}$ levels (median [range]) were observed in the $\mathrm{A}+/ \mathrm{T}+$ group (637 ng/L [354; 1780]; $85 \mathrm{ng} / \mathrm{L}[49 ; 197])$ compared with the A-/T+ group (458 ng/L [353; 742]; $69 \mathrm{ng} / \mathrm{L}[46 ; 116]$; Table 1B). A $\beta$ levels did not differ between the A+/T+ $(381 \mathrm{ng} / \mathrm{L}[159 ; 587])$ and A+/T- (421 ng/L [259;590]) group. Slightly higher levels of A $\beta$ were observed in the A-/T+ (903 ng/L [607;1580]) vs the A-/T- $(790 \mathrm{ng} / \mathrm{L}$ [600;1180]) group $(\mathrm{p}<0.001)$. Participants characterized as $\mathrm{A}-/ \mathrm{T}+$ are considered participants with Suspected Non-A $\beta$ Pathology (SNAP) (Supplemental Fig. S4A and S4B).

The A+/T+ participants presented with a significantly lower MMSE $(26$ [14;30], p<0.001) (Table 1B), RBANS Total Scale score (76 [47;135], $\mathrm{p}<0.001$; Table 1B and Fig. 1B) and RBANS Index scores (except visuospatial index) compared with all the other groups $(\mathrm{p}<0.001$; Supplemental Table S2). The highest impairment (lowest score) was observed on Delayed Memory index, followed by Attention, Immediate Memory, Language Index, and Visuospatial Index (no significant difference with the A+/T- group; Supplemental Table S2.) The A+/T-, A-/T+ or A-/T- group did not differ from each other based on the RBANS Total Scale score or RBANS Index scores.

\subsection{Correlation between CSF tau levels (t-tau and p-tau181P) and cognitive impairment}

In the overall group, the RBANS Total Scale score showed a moderate negative correlation to t$\operatorname{tau}(\mathrm{n}=246 ; \mathrm{r}=-0.434 ; \mathrm{p}<0.001 ;$ Fig. $2 \mathrm{~A}$ and Table 2$)$ and $\mathrm{p}-\operatorname{tau}_{181 \mathrm{P}}(\mathrm{n}=246 ; \mathrm{r}=-0.389 ; \mathrm{p}<0.001$ [Table 2]). However, when classified by A $\beta$ status, the RBANS Total Scale score showed a moderate negative correlation to $t$-tau in the $A+$ participants $(n=139 ; r=-0.451, p<0.001)$ and not in the A-participants $(n=107 ; r=0.137, p=0.16)$ (Fig. 2B). The individual RBANS index scores (Table 2) showed similar observations with only significant negative correlations with t-tau 
levels in the A+ group and not in the A-group with the strongest negative correlation observed in the $\mathrm{A}+$ group for the attention index $(\mathrm{r}=-0.438, \mathrm{p}<0.001)$ and delayed memory index $(\mathrm{r}=-0.431, \mathrm{p}<0.001)$, followed by the immediate memory index $(\mathrm{r}=-0.327, \mathrm{p}<0.001)$, language $(\mathrm{r}=-0.261, \mathrm{p}<0.01)$ and visuospatial index $(\mathrm{r}=-0.254, \mathrm{p}<0.01)$. Similar findings were observed for $\mathrm{p}-\operatorname{tau}_{181 \mathrm{P}}($ Table 2$)$.

Both t-tau $(\mathrm{p}<0.0001)$ and the interaction of $A \beta_{1-42}$ with t-tau $(\mathrm{p}=0.006)$ were statistically significant in their effect on RBANS, but not $A \beta_{1-42}$ (Supplemental Table S3A). When the regression included independent variables for age and sex ( 0 for female, 1 for male), again both ttau $(p<0.0001)$ the interaction of $A \beta_{1-42}$ with $t$-tau were significant $(p=0.0127)$, but not the other variables (Supplemental Table S3B). APOE $\varepsilon 4$ carrier status was not included in the model since it was only available for the A+ participants. Similar findings were observed for $\mathrm{p}$-tau $181 \mathrm{P}$ (Supplemental Tables S3C and S3D). 


\section{Discussion}

We examined the role of tau and its possible interplay with $\mathrm{A} \beta$, measured based on CSF biomarkers $\left(\mathrm{A} \beta_{1-42}, \mathrm{t}\right.$-tau and $\mathrm{p}$-tau $\left.181 \mathrm{P}\right)$, on cognitive performance (RBANS) as a clinical marker in participants in the early $\mathrm{AD}$ continuum ranging from normal to preclinical $\mathrm{AD}$ and $\mathrm{pAD}$. Original screening paradigm allowed classification of participants based on their clinical function and evidence of $\mathrm{A} \beta$ pathology along the early stages of the $\mathrm{AD}$ continuum. In addition, across the early AD continuum, CSF A $\beta$ levels were shown to plateau while tau levels steadily increased with increased cognitive impairment. In the current study, the correlation of cognitive/memory impairment with CSF tau was dependent on CSF A $\beta$ levels indicative for A $\beta$ pathology, suggesting the importance of an interplay between both hallmark features of the disease. In addition, both tau and the interaction of $A \beta_{1-42}$ with tau were significant in their effect on RBANS, but not $A \beta_{1-42}$ alone.

Earlier publications have suggested that tau correlates with, and is predictive of, clinical function and cognitive impairment (Nelson et al., 2009). In the current study, clinical function aligned with cognitive performance (Hobson et al., 2010). The pAD group presented an RBANS Total Scale score and RBANS Index scores in line with AD pathology (Randolph et al., 1998), while the preclinical AD group presented a normal cognitive profile, confirming the usability of the RBANS as a cognitive screening tool in AD (Duff et al., 2008).

CSF tau levels (t-tau and p-tau $181 \mathrm{P}$ ) increased across stages in the early AD continuum (preclinical and pAD) with the pAD group showing highest tau levels. No further decline in CSF $\mathrm{A} \beta$ levels was observed across early AD stages, suggesting that CSF A $\beta$ levels may plateau early while CSF tau levels further increase and may drive cognitive decline (Andersson et al., 2008; Buchhave et al., 2012). High CSF levels of t-tau and p-tau $181 \mathrm{P}$ have been associated with a distinct cognitive profile with more severe impairment of memory and mental speed, and 
executive functions, not explained by disease severity (van der Vlies et al., 2009). In contrast, the amount of $A \beta$ accumulation or its removal by immunotherapy has been shown not to correlate with cognitive performance (Giannakopoulos et al., 2003; Salloway et al., 2014). In addition, substantial $\mathrm{A} \beta$ deposition may also occur without affecting cognitive performance overall (PerezNievas et al., 2013). Based on the above, $A \beta$ pathology appears to be an early marker of incident disease.

The observation of elevated CSF tau levels already in the preclinical AD stage is in line with previous studies (ㅂoglund et al., 2017; Mattsson et al., 2017; Toledo et al., 2013; $\underline{\text { Vos et al., }}$ $\underline{2013}$ ), and similar as to further elevated CSF tau levels along to early AD continuum (Andersson et al., 2008; Stefani et al., 2006; Toledo et al., 2013). However this finding is not observed in some studies (Insel et al., 2018). The CSF tau elevations may indicate that the preclinical and pAD groups are already in a state of neuronal injury/degeneration.

CSF A $\beta$ levels did not significantly differ between $A+$ populations, despite the fact that $\mathrm{pAD}$ participants presumably have more accumulated brain $\mathrm{A} \beta$ pathology compared to preclinical $\mathrm{AD}$ participants. CSF A $\beta$ and $\mathrm{A} \beta$ PET measures do not change precisely in parallel as they measure different aspects of the AD amyloid pathology (Toledo et al., 2015) . CSF A $\beta$ significantly decreases early in preclinical $\mathrm{AD}$ and then remains rather stable, whereas the $\mathrm{A} \beta$ PET signal would continuously increase in the non-demented AD stages, lowering again in the symptomatic stage of the disease (Kadir et al., 2012). In contrast to the pAD group, the MCI group presented with a less severe and slightly distinct cognitive profile from the pAD group. The overall MCI group presented normal CSF tau levels indicating that the cognitive impairment may have another etiology than AD. 
When classifying participants solely based on their CSF biomarker profile, it became apparent that CSF A $\beta$ or tau levels alone did not result in significant cognitive changes compared with the participants having normal CSF levels. (Pascoal et al., 2017), This suggests that elevated CSF tau levels are essential for learning and memory deficits in the presence of decreased CSF A $\beta$ levels indicative of amyloid pathology in AD (Desikan et al., 2012; Roberson et al., 2007). While T+ participants were observed in both A+ and A- groups, high CSF tau levels were only observed in $A+$ participants, suggesting that $A \beta$ pathology may further drive or advance CSF tau levels resulting in synergistic rather than additive effects (Pascoal et al., 2017). Recent in vivo labelling data suggest that neurons may respond to $A \beta$ pathology by increasing their secretion of both total and phosphorylated tau (Sato et al., 2018) Such neurons may be at increased risk of developing tangles and eventually degenerate but this may be downstream of the tau dysmetabolism that the biomarkers reflect.

In the current analysis, cognitive/memory performance correlated with CSF tau levels (t-tau and p-tau 181 P) in the early stages of the AD continuum (Rami et al., 2011; Reijs et al., 2017).

However, the correlation observed is $A \beta$ dependent and only present in the $A \beta$ positive group,. This correlation with CSF tau levels (t-tau and p-tau $181 \mathrm{P}$ ) was also observed for all relevant RBANS subdomains, Delayed Memory, Attention and Immediate Memory on the background of $A \beta$. A recent meta-analysis of preclinical data in transgenic mice further supports a primary role for tau in cognitive decline in preclinical $\mathrm{AD}$, while $\mathrm{A} \beta$ may rather play an indirect role in the development of NFT (Huber et al., 2018). In contrast, other groups have observed the opposite, showing a correlation of cognitive impairment with $\mathrm{A} \beta$ on the backbone of tau in preclinical AD and MCI (Desikan et al., 2012; Haldenwanger et al., 2010).

The data presented in this study are suggestive of an interplay between $\mathrm{A} \beta$ and tau in relation to cognitive impairment/decline in $\mathrm{AD}$. Both are required to induce the impairment while tau 
pathology is driving the level of impairment. Supportive hereof is that widespread cortical tau pathology (Braak stage $\geq 3$ ) has commonly been observed in patients with $A \beta$ plaques, although not in patients without plaques, supporting the hypothesis that $A \beta$ aggregation is required for the appearance of high cortical tau pathology (Knopman et al., 2003; Petersen et al., 2006; Price and Morris, 1999). In addition, significant interactions between CSF A $\beta$ and CSF p-tau levels have been shown to affect brain structure (MRI) only in preclinical AD patients positive for both CSF $\mathrm{A} \beta$ and tau. This interaction is suggestive of a 2-phase phenomon of pathological cortical thickening associated with low $\mathrm{A} \beta$, followed by atrophy and cognitive decline associated with abnormal (high) CSF p-tau levels (Fortea et al., 2014).

Recent preclinical studies have highlighted several possible pathways by which $A \beta$ could directly and indirectly influence the levels of tau, induce hyperphosphorylation of tau and the formation of neurofibrillary tangles (Gotz et al., 2001; Nisbet et al., 2015). In in vitro and in vivo (transgenic mice) models, inhibition of $\mathrm{A} \beta$ production by beta and gamma secretases elicits $\mathrm{A} \beta$ aggregation and subsequent tau pathology (incl. CSF tau) suggesting tau to be downstream effect

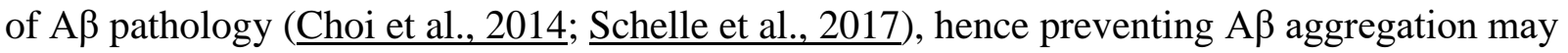
directly affect tau pathologyOn the other hand, both $\mathrm{A} \beta$ and tau have shown self-propagation capabilities in animal models (Jucker and Walker, 2011). Extracellular p-tau seeds can induce tauopathy in neurons, supporting the hypothesis that tauopathy can spread in a prion-like fashion between neurons, a cascade that could be potentially initiated or accelerated by A $\beta$ pathology (Goedert et al., 2017; Nussbaum et al., 2013). In such a case, optimal treatment to prevent cognitive decline/impairment should ideally start prior to tau reaching pathological (high) levels in CSF or before reaching levels associated with cognitive decline, hence in preclinical AD stage 1 or 2 (Sperling et al., 2011), highlighting the importance for the inclusion of biomarkers in the diagnosis of preclinical AD. Current ongoing studies in preclinical AD targeting A $\beta$ (e.g., BACE 
inhibitor studies) will provide further insight into this possible interaction between $A \beta$ and tau and the ability to prevent cognitive decline and increases in tau pathology by A $\beta$ inhibition.

As all participants were screened in light of an AD clinical trial, the population included may not be representative for the overall continuum as some patients may have presented with subjective memory complaints. However, data presented clearly demonstrated that based on the screening paradigm applied, different population groups could be identified from normal controls to preclinical AD and ppAD and even MCI . Secondly, this study only reports cross-sectional data, and longitudinal data further supporting the hypothesis that tau pathology correlates to cognitive decline on the backbone of $\mathrm{A} \beta$ (CSF) are needed. Furthermore, although similar correlations between CSF tau and cognitive impairment have been reported before, opposite results have also been reported, still describing an interaction between $A \beta$ and tau in the opposite direction.(Desikan et al., 2012) These differences may be explained by the application of different cognitive measures. Where most studies opted for the classical clinical and cognitive measures such as MMSE, CDR and ADAS-cog, we applied next to the CDR and MMSE, for the RBANS as a sensitive and specific measure for cognitive function, currently applied in several multicentre trials in $\mathrm{AD}$, which may clarify some of the differences observed.

\section{Conclusion}

Across the early stages of the AD continuum, cognitive/memory performance correlated well with CSF tau levels. However, the observed correlation is A $\beta$-dependent and only present in the A $\beta$-positive group indicating the importance of a possible interplay between both neuropathological hallmarks of $\mathrm{AD}$. 


\section{References}

Aisen, P.S., Cummings, J., Jack, C.R., Jr., Morris, J.C., Sperling, R., Frolich, L., Jones, R.W., Dowsett, S.A., Matthews, B.R., Raskin, J., Scheltens, P., Dubois, B., 2017. On the path to 2025: understanding the Alzheimer's disease continuum. Alzheimers Res Ther 9(1), 60.

Andersson, C., Blennow, K., Almkvist, O., Andreasen, N., Engfeldt, P., Johansson, S.E., Lindau, M., Eriksdotter-Jonhagen, M., 2008. Increasing CSF phospho-tau levels during cognitive decline and progression to dementia. Neurobiol Aging 29(10), 1466-1473.

Berg, L., McKeel, D.W., Jr., Miller, J.P., Baty, J., Morris, J.C., 1993. Neuropathological indexes of Alzheimer's disease in demented and nondemented persons aged 80 years and older. Arch Neurol 50(4), 349-358.

Bloom, G.S., 2014. Amyloid-beta and tau: the trigger and bullet in Alzheimer disease pathogenesis. JAMA Neurol 71(4), 505-508.

Braak, H., Alafuzoff, I., Arzberger, T., Kretzschmar, H., Del Tredici, K., 2006. Staging of Alzheimer disease-associated neurofibrillary pathology using paraffin sections and immunocytochemistry. Acta Neuropathol 112(4), 389-404.

Buchhave, P., Minthon, L., Zetterberg, H., Wallin, A.K., Blennow, K., Hansson, O., 2012. Cerebrospinal fluid levels of beta-amyloid 1-42, but not of tau, are fully changed already 5 to 10 years before the onset of Alzheimer dementia. Archives of general psychiatry 69(1), 98-106.

Burke, W.J., Miller, J.P., Rubin, E.H., Morris, J.C., Coben, L.A., Duchek, J., Wittels, I.G., Berg, L., 1988. Reliability of the Washington University Clinical Dementia Rating. Arch Neurol 45(1), 31-32.

Choi, S.H., Kim, Y.H., Hebisch, M., Sliwinski, C., Lee, S., D'Avanzo, C., Chen, H., Hooli, B., Asselin, C., Muffat, J., Klee, J.B., Zhang, C., Wainger, B.J., Peitz, M., Kovacs, D.M., Woolf, C.J., Wagner, S.L., Tanzi, R.E., Kim, D.Y., 2014. A three-dimensional human neural cell culture model of Alzheimer's disease. Nature 515(7526), 274-278.

Desikan, R.S., McEvoy, L.K., Thompson, W.K., Holland, D., Brewer, J.B., Aisen, P.S., Sperling, R.A., Dale, A.M., Alzheimer's Disease Neuroimaging, I., 2012. Amyloid-beta--associated clinical decline occurs only in the presence of elevated P-tau. Arch Neurol 69(6), 709-713.

Dubois, B., Feldman, H.H., Jacova, C., Hampel, H., Molinuevo, J.L., Blennow, K., DeKosky, S.T., Gauthier, S., Selkoe, D., Bateman, R., Cappa, S., Crutch, S., Engelborghs, S., Frisoni, G.B., Fox, N.C., Galasko, D., Habert, M.O., Jicha, G.A., Nordberg, A., Pasquier, F., Rabinovici, G., Robert, P., Rowe, C., Salloway, S., Sarazin, M., Epelbaum, S., de Souza, L.C., Vellas, B., Visser, P.J., Schneider, L., Stern, Y., Scheltens, P., Cummings, J.L., 2014. Advancing research diagnostic criteria for Alzheimer's disease: the IWG-2 criteria. Lancet Neurol 13(6), 614-629.

Dubois, B., Hampel, H., Feldman, H.H., Scheltens, P., Aisen, P., Andrieu, S., Bakardjian, H., Benali, H., Bertram, L., Blennow, K., Broich, K., Cavedo, E., Crutch, S., Dartigues, J.F., Duyckaerts, C., Epelbaum, S., Frisoni, G.B., Gauthier, S., Genthon, R., Gouw, A.A., Habert, M.O., Holtzman, D.M., Kivipelto, M., Lista, S., Molinuevo, J.L., O'Bryant, S.E., Rabinovici, 
G.D., Rowe, C., Salloway, S., Schneider, L.S., Sperling, R., Teichmann, M., Carrillo, M.C., Cummings, J., Jack, C.R., Jr., Proceedings of the Meeting of the International Working, G., the American Alzheimer's Association on "The Preclinical State of, A.D., July, Washington Dc, U.S.A., 2016. Preclinical Alzheimer's disease: Definition, natural history, and diagnostic criteria. Alzheimers Dement 12(3), 292-323.

Duff, K., Humphreys Clark, J.D., O'Bryant, S.E., Mold, J.W., Schiffer, R.B., Sutker, P.B., 2008. Utility of the RBANS in detecting cognitive impairment associated with Alzheimer's disease: sensitivity, specificity, and positive and negative predictive powers. Arch Clin Neuropsychol 23(5), 603-612.

Folstein, M.F., Folstein, S.E., McHugh, P.R., 1975. "Mini-mental state". A practical method for grading the cognitive state of patients for the clinician. J Psychiatr Res 12(3), 189-198.

Fortea, J., Vilaplana, E., Alcolea, D., Carmona-Iragui, M., Sanchez-Saudinos, M.B., Sala, I., Anton-Aguirre, S., Gonzalez, S., Medrano, S., Pegueroles, J., Morenas, E., Clarimon, J., Blesa, R., Lleo, A., Alzheimer's Disease Neuroimaging, I., 2014. Cerebrospinal fluid beta-amyloid and phospho-tau biomarker interactions affecting brain structure in preclinical Alzheimer disease. Ann Neurol 76(2), 223-230.

Giannakopoulos, P., Herrmann, F.R., Bussiere, T., Bouras, C., Kovari, E., Perl, D.P., Morrison, J.H., Gold, G., Hof, P.R., 2003. Tangle and neuron numbers, but not amyloid load, predict cognitive status in Alzheimer's disease. Neurology 60(9), 1495-1500.

Goedert, M., Masuda-Suzukake, M., Falcon, B., 2017. Like prions: the propagation of aggregated tau and alpha-synuclein in neurodegeneration. Brain 140(2), 266-278.

Gotz, J., Chen, F., van Dorpe, J., Nitsch, R.M., 2001. Formation of neurofibrillary tangles in P3011 tau transgenic mice induced by Abeta 42 fibrils. Science 293(5534), 1491-1495.

Haldenwanger, A., Eling, P., Kastrup, A., Hildebrandt, H., 2010. Correlation between cognitive impairment and CSF biomarkers in amnesic MCI, non-amnesic MCI, and Alzheimer's disease. J Alzheimers Dis 22(3), 971-980.

Hardy, J., Selkoe, D.J., 2002. The amyloid hypothesis of Alzheimer's disease: progress and problems on the road to therapeutics. Science 297(5580), 353-356.

Hobson, V.L., Hall, J.R., Humphreys-Clark, J.D., Schrimsher, G.W., O'Bryant, S.E., 2010. Identifying functional impairment with scores from the repeatable battery for the assessment of neuropsychological status (RBANS). Int J Geriatr Psychiatry 25(5), 525-530.

Hoglund, K., Kern, S., Zettergren, A., Borjesson-Hansson, A., Zetterberg, H., Skoog, I., Blennow, K., 2017. Preclinical amyloid pathology biomarker positivity: effects on tau pathology and neurodegeneration. Transl Psychiatry 7(1), e995.

Hollander, M., and Wolfe, D. A. , 1999. Nonparametric Statistical Methods. , 2nd ed. John Wiley \& Sons, New York. 
Huber, C.M., Yee, C., May, T., Dhanala, A., Mitchell, C.S., 2018. Cognitive Decline in Preclinical Alzheimer's Disease: Amyloid-Beta versus Tauopathy. J Alzheimers Dis 61(1), 265281.

Insel, P.S., Hansson, O., Mackin, R.S., Weiner, M., Mattsson, N., Alzheimer's Disease Neuroimaging, I., 2018. Amyloid pathology in the progression to mild cognitive impairment. Neurobiol Aging 64, 76-84.

Jack, C.R., Jr., Bennett, D.A., Blennow, K., Carrillo, M.C., Dunn, B., Haeberlein, S.B., Holtzman, D.M., Jagust, W., Jessen, F., Karlawish, J., Liu, E., Molinuevo, J.L., Montine, T., Phelps, C., Rankin, K.P., Rowe, C.C., Scheltens, P., Siemers, E., Snyder, H.M., Sperling, R., Contributors, 2018. NIA-AA Research Framework: Toward a biological definition of Alzheimer's disease. Alzheimers Dement 14(4), 535-562.

Jack, C.R., Jr., Knopman, D.S., Jagust, W.J., Petersen, R.C., Weiner, M.W., Aisen, P.S., Shaw, L.M., Vemuri, P., Wiste, H.J., Weigand, S.D., Lesnick, T.G., Pankratz, V.S., Donohue, M.C., Trojanowski, J.Q., 2013. Tracking pathophysiological processes in Alzheimer's disease: an updated hypothetical model of dynamic biomarkers. Lancet Neurol 12(2), 207-216.

Jucker, M., Walker, L.C., 2011. Pathogenic protein seeding in Alzheimer disease and other neurodegenerative disorders. Ann Neurol 70(4), 532-540.

Jucker, M., Walker, L.C., 2013. Self-propagation of pathogenic protein aggregates in neurodegenerative diseases. Nature 501(7465), 45-51.

Kadir, A., Almkvist, O., Forsberg, A., Wall, A., Engler, H., Langstrom, B., Nordberg, A., 2012. Dynamic changes in PET amyloid and FDG imaging at different stages of Alzheimer's disease. Neurobiol Aging 33(1), 198 e191-114.

Karran, E., Mercken, M., De Strooper, B., 2011. The amyloid cascade hypothesis for Alzheimer's disease: an appraisal for the development of therapeutics. Nat Rev Drug Discov 10(9), 698-712.

Knopman, D.S., Caselli, R.J., 2012. Appraisal of cognition in preclinical Alzheimer's disease: a conceptual review. Neurodegener Dis Manag 2(2), 183-195.

Knopman, D.S., Parisi, J.E., Salviati, A., Floriach-Robert, M., Boeve, B.F., Ivnik, R.J., Smith, G.E., Dickson, D.W., Johnson, K.A., Petersen, L.E., McDonald, W.C., Braak, H., Petersen, R.C., 2003. Neuropathology of cognitively normal elderly. J Neuropathol Exp Neurol 62(11), 1087 1095.

Levy-Lahad, E., Wasco, W., Poorkaj, P., Romano, D.M., Oshima, J., Pettingell, W.H., Yu, C.E., Jondro, P.D., Schmidt, S.D., Wang, K., et al., 1995. Candidate gene for the chromosome 1 familial Alzheimer's disease locus. Science 269(5226), 973-977.

Mattsson, N., Scholl, M., Strandberg, O., Smith, R., Palmqvist, S., Insel, P.S., Hagerstrom, D., Ohlsson, T., Zetterberg, H., Jogi, J., Blennow, K., Hansson, O., 2017. (18)F-AV-1451 and CSF T-tau and P-tau as biomarkers in Alzheimer's disease. EMBO Mol Med 9(9), 1212-1223. 
Morris, J.C., Ernesto, C., Schafer, K., Coats, M., Leon, S., Sano, M., Thal, L.J., Woodbury, P., Study, t.A.s.D.C., 1997. Clinical Dementia Rating training and reliability in multicenter studies: The Alzheimer's Disease Cooperative Study experience. Neurology 48, 1508-1510.

Musiek, E.S., Holtzman, D.M., 2015. Three dimensions of the amyloid hypothesis: time, space and 'wingmen'. Nat Neurosci 18(6), 800-806.

Nelson, P.T., Alafuzoff, I., Bigio, E.H., Bouras, C., Braak, H., Cairns, N.J., Castellani, R.J., Crain, B.J., Davies, P., Del Tredici, K., Duyckaerts, C., Frosch, M.P., Haroutunian, V., Hof, P.R., Hulette, C.M., Hyman, B.T., Iwatsubo, T., Jellinger, K.A., Jicha, G.A., Kovari, E., Kukull, W.A., Leverenz, J.B., Love, S., Mackenzie, I.R., Mann, D.M., Masliah, E., McKee, A.C., Montine, T.J., Morris, J.C., Schneider, J.A., Sonnen, J.A., Thal, D.R., Trojanowski, J.Q., Troncoso, J.C., Wisniewski, T., Woltjer, R.L., Beach, T.G., 2012. Correlation of Alzheimer disease neuropathologic changes with cognitive status: a review of the literature. J Neuropathol Exp Neurol 71(5), 362-381.

Nelson, P.T., Braak, H., Markesbery, W.R., 2009. Neuropathology and cognitive impairment in Alzheimer disease: a complex but coherent relationship. J Neuropathol Exp Neurol 68(1), 1-14.

Nisbet, R.M., Polanco, J.C., Ittner, L.M., Gotz, J., 2015. Tau aggregation and its interplay with amyloid-beta. Acta Neuropathol 129(2), 207-220.

Nussbaum, J.M., Seward, M.E., Bloom, G.S., 2013. Alzheimer disease: a tale of two prions. Prion 7(1), 14-19.

Palmqvist, S., Zetterberg, H., Blennow, K., Vestberg, S., Andreasson, U., Brooks, D.J., Owenius, R., Hagerstrom, D., Wollmer, P., Minthon, L., Hansson, O., 2014. Accuracy of brain amyloid detection in clinical practice using cerebrospinal fluid beta-amyloid 42: a cross-validation study against amyloid positron emission tomography. JAMA Neurol 71(10), 1282-1289.

Paquet, C., Bouaziz-Amar, E., Cognat, E., Volpe-Gillot, L., Haddad, V., Mahieux, F., Dekimeche, S., Defontaines, B., Chabriat, H., Belin, C., Texeira, A., Goutagny, S., Questel, F., Azuar, J., Sellier, P.O., Laplanche, J.L., Hugon, J., Dumurgier, J., 2018. Distribution of Cerebrospinal Fluid Biomarker Profiles in Patients Explored for Cognitive Disorders. Journal of Alzheimer's disease : JAD 64(3), 889-897.

Pascoal, T.A., Mathotaarachchi, S., Shin, M., Benedet, A.L., Mohades, S., Wang, S., Beaudry, T., Kang, M.S., Soucy, J.P., Labbe, A., Gauthier, S., Rosa-Neto, P., Alzheimer's Disease Neuroimaging, I., 2017. Synergistic interaction between amyloid and tau predicts the progression to dementia. Alzheimers Dement 13(6), 644-653.

Perez-Nievas, B.G., Stein, T.D., Tai, H.C., Dols-Icardo, O., Scotton, T.C., Barroeta-Espar, I., Fernandez-Carballo, L., de Munain, E.L., Perez, J., Marquie, M., Serrano-Pozo, A., Frosch, M.P., Lowe, V., Parisi, J.E., Petersen, R.C., Ikonomovic, M.D., Lopez, O.L., Klunk, W., Hyman, B.T., Gomez-Isla, T., 2013. Dissecting phenotypic traits linked to human resilience to Alzheimer's pathology. Brain 136(Pt 8), 2510-2526. 
Petersen, R.C., Parisi, J.E., Dickson, D.W., Johnson, K.A., Knopman, D.S., Boeve, B.F., Jicha, G.A., Ivnik, R.J., Smith, G.E., Tangalos, E.G., Braak, H., Kokmen, E., 2006. Neuropathologic features of amnestic mild cognitive impairment. Arch Neurol 63(5), 665-672.

Pontecorvo, M.J., Devous, M.D., Sr., Navitsky, M., Lu, M., Salloway, S., Schaerf, F.W., Jennings, D., Arora, A.K., McGeehan, A., Lim, N.C., Xiong, H., Joshi, A.D., Siderowf, A., Mintun, M.A., investigators, F.A.-A., 2017. Relationships between flortaucipir PET tau binding and amyloid burden, clinical diagnosis, age and cognition. Brain 140(3), 748-763.

Price, J.L., Morris, J.C., 1999. Tangles and plaques in nondemented aging and "preclinical" Alzheimer's disease. Ann Neurol 45(3), 358-368.

Rami, L., Fortea, J., Bosch, B., Sole-Padulles, C., Llado, A., Iranzo, A., Sanchez-Valle, R., Molinuevo, J.L., 2011. Cerebrospinal fluid biomarkers and memory present distinct associations along the continuum from healthy subjects to AD patients. J Alzheimers Dis 23(2), 319-326.

Randolph, C., Tierney, M.C., Mohr, E., Chase, T.N., 1998. The Repeatable Battery for the Assessment of Neuropsychological Status (RBANS): preliminary clinical validity. J Clin Exp Neuropsychol 20(3), 310-319.

Reijs, B.L.R., Ramakers, I., Kohler, S., Teunissen, C.E., Koel-Simmelink, M., Nathan, P.J., Tsolaki, M., Wahlund, L.O., Waldemar, G., Hausner, L., Vandenberghe, R., Johannsen, P., Blackwell, A., Vanderstichele, H., Verhey, F., Visser, P.J., 2017. Memory Correlates of Alzheimer's Disease Cerebrospinal Fluid Markers: A Longitudinal Cohort Study. J Alzheimers Dis 60(3), 1119-1128.

Roberson, E.D., Scearce-Levie, K., Palop, J.J., Yan, F., Cheng, I.H., Wu, T., Gerstein, H., Yu, G.Q., Mucke, L., 2007. Reducing endogenous tau ameliorates amyloid beta-induced deficits in an Alzheimer's disease mouse model. Science 316(5825), 750-754.

Rogaev, E.I., Sherrington, R., Rogaeva, E.A., Levesque, G., Ikeda, M., Liang, Y., Chi, H., Lin, C., Holman, K., Tsuda, T., et al., 1995. Familial Alzheimer's disease in kindreds with missense mutations in a gene on chromosome 1 related to the Alzheimer's disease type 3 gene. Nature 376(6543), 775-778.

Salloway, S., Sperling, R., Fox, N.C., Blennow, K., Klunk, W., Raskind, M., Sabbagh, M., Honig, L.S., Porsteinsson, A.P., Ferris, S., Reichert, M., Ketter, N., Nejadnik, B., Guenzler, V., Miloslavsky, M., Wang, D., Lu, Y., Lull, J., Tudor, I.C., Liu, E., Grundman, M., Yuen, E., Black, R., Brashear, H.R., Bapineuzumab, Clinical Trial, I., 2014. Two phase 3 trials of bapineuzumab in mild-to-moderate Alzheimer's disease. N Engl J Med 370(4), 322-333.

Sato, C., Barthelemy, N.R., Mawuenyega, K.G., Patterson, B.W., Gordon, B.A., JockelBalsarotti, J., Sullivan, M., Crisp, M.J., Kasten, T., Kirmess, K.M., Kanaan, N.M., Yarasheski, K.E., Baker-Nigh, A., Benzinger, T.L.S., Miller, T.M., Karch, C.M., Bateman, R.J., 2018. Tau Kinetics in Neurons and the Human Central Nervous System. Neuron 97(6), 1284-1298 e1287.

Schelle, J., Hasler, L.M., Gopfert, J.C., Joos, T.O., Vanderstichele, H., Stoops, E., Mandelkow, E.M., Neumann, U., Shimshek, D.R., Staufenbiel, M., Jucker, M., Kaeser, S.A., 2017. Prevention 
of tau increase in cerebrospinal fluid of APP transgenic mice suggests downstream effect of BACE1 inhibition. Alzheimers Dement 13(6), 701-709.

Sherrington, R., Rogaev, E.I., Liang, Y., Rogaeva, E.A., Levesque, G., Ikeda, M., Chi, H., Lin, C., Li, G., Holman, K., Tsuda, T., Mar, L., Foncin, J.F., Bruni, A.C., Montesi, M.P., Sorbi, S., Rainero, I., Pinessi, L., Nee, L., Chumakov, I., Pollen, D., Brookes, A., Sanseau, P., Polinsky, R.J., Wasco, W., Da Silva, H.A., Haines, J.L., Perkicak-Vance, M.A., Tanzi, R.E., Roses, A.D., Fraser, P.E., Rommens, J.M., St George-Hyslop, P.H., 1995. Cloning of a gene bearing missense mutations in early-onset familial Alzheimer's disease. Nature 375(6534), 754-760.

Sperling, R.A., Aisen, P.S., Beckett, L.A., Bennett, D.A., Craft, S., Fagan, A.M., Iwatsubo, T., Jack, C.R., Jr., Kaye, J., Montine, T.J., Park, D.C., Reiman, E.M., Rowe, C.C., Siemers, E., Stern, Y., Yaffe, K., Carrillo, M.C., Thies, B., Morrison-Bogorad, M., Wagster, M.V., Phelps, C.H., 2011. Toward defining the preclinical stages of Alzheimer's disease: recommendations from the National Institute on Aging-Alzheimer's Association workgroups on diagnostic guidelines for Alzheimer's disease. Alzheimers Dement 7(3), 280-292.

Stefani, A., Martorana, A., Bernardini, S., Panella, M., Mercati, F., Orlacchio, A., Pierantozzi, M., 2006. CSF markers in Alzheimer disease patients are not related to the different degree of cognitive impairment. J Neurol Sci 251(1-2), 124-128.

Timmers, M., Streffer, J.R., Russu, A., Tominaga, Y., Shimizu, H., Shiraishi, A., Tatikola, K., Smekens, P., Borjesson-Hanson, A., Andreasen, N., Matias-Guiu, J., Baquero, M., Boada, M., Tesseur, I., Tritsmans, L., Van Nueten, L., Engelborghs, S., 2018. Pharmacodynamics of atabecestat (JNJ-54861911), an oral BACE1 inhibitor in patients with early Alzheimer's disease: randomized, double-blind, placebo-controlled study. Alzheimers Res Ther 10(1), 85.

Toledo, J.B., Bjerke, M., Da, X., Landau, S.M., Foster, N.L., Jagust, W., Jack, C., Jr., Weiner, M., Davatzikos, C., Shaw, L.M., Trojanowski, J.Q., Alzheimer's Disease Neuroimaging Initiative, I., 2015. Nonlinear Association Between Cerebrospinal Fluid and Florbetapir F-18 beta-Amyloid Measures Across the Spectrum of Alzheimer Disease. JAMA Neurol 72(5), 571581.

Toledo, J.B., Xie, S.X., Trojanowski, J.Q., Shaw, L.M., 2013. Longitudinal change in CSF Tau and Abeta biomarkers for up to 48 months in ADNI. Acta Neuropathol 126(5), 659-670.

van der Vlies, A.E., Verwey, N.A., Bouwman, F.H., Blankenstein, M.A., Klein, M., Scheltens, P., van der Flier, W.M., 2009. CSF biomarkers in relationship to cognitive profiles in Alzheimer disease. Neurology 72(12), 1056-1061.

Villemagne, V.L., Burnham, S., Bourgeat, P., Brown, B., Ellis, K.A., Salvado, O., Szoeke, C., Macaulay, S.L., Martins, R., Maruff, P., Ames, D., Rowe, C.C., Masters, C.L., Australian Imaging, B., Lifestyle Research, G., 2013. Amyloid beta deposition, neurodegeneration, and cognitive decline in sporadic Alzheimer's disease: a prospective cohort study. Lancet Neurol 12(4), 357-367.

Vos, S.J., Xiong, C., Visser, P.J., Jasielec, M.S., Hassenstab, J., Grant, E.A., Cairns, N.J., Morris, J.C., Holtzman, D.M., Fagan, A.M., 2013. Preclinical Alzheimer's disease and its outcome: a longitudinal cohort study. Lancet Neurol 12(10), 957-965. 


\section{Tables}

Table 1A Demographics and biomarker summary by CDR and A $\left(A+\right.$ or $\left.A^{-}\right)$status

\begin{tabular}{|c|c|c|c|c|c|}
\hline & $\begin{array}{c}\text { Control } \\
(\mathrm{CDR}=0 ; \mathrm{A}-) \\
\mathrm{N}=69\end{array}$ & $\begin{array}{c}\text { Preclinical AD } \\
\text { (CDR=0; A+) } \\
\text { N=33 }\end{array}$ & $\begin{array}{c}\text { MCI } \\
\left(C D R \geq 0.5 ; A^{-}\right) \\
\text {N=38 }\end{array}$ & $\begin{array}{c}\text { Prodromal AD } \\
(C D R \geq 0.5 ; A+) \\
\text { N=106 }\end{array}$ & $\begin{array}{c}\text { Total } \\
\mathrm{N}=\mathbf{2 4 6}\end{array}$ \\
\hline Women, n (\%) & $37(53.6)$ & $14(42.4)$ & $19(50)$ & $57(53.8)$ & $127(51.6)$ \\
\hline Age, mean (SD), years & $67.9(5.62)$ & $69.8(5.54)$ & $67.0(6.77)$ & $69.3(7.08)$ & $68.6(6.49)$ \\
\hline \multicolumn{6}{|l|}{ Age group, $\mathrm{n}(\%)$} \\
\hline$<65$ & $18(26.1)$ & $7(21.2)$ & 12 (31.6) & $26(24.5)$ & $63(25.6)$ \\
\hline$\geq 65-<75$ & $44(63.8)$ & $17(51.5)$ & $22(57.9)$ & $52(49.1)$ & $135(54.9)$ \\
\hline$\geq 75$ & $7(10.1)$ & $9(27.3)$ & $4(10.5)$ & $28(26.4)$ & $48(19.5)$ \\
\hline \multicolumn{6}{|l|}{ Race, n (\%) } \\
\hline White & $68(98.6)$ & $33(100)$ & $38(100)$ & $103(97.2)$ & $242(98.4)$ \\
\hline $\begin{array}{l}\text { Black or African } \\
\text { American }\end{array}$ & $1(1.4)$ & 0 & 0 & 0 & $1(0.4)$ \\
\hline Other & 0 & 0 & 0 & $3(2.8)$ & $3(1.2)$ \\
\hline Weight, mean (SD), kg & $74.1(14.28)$ & $72.9(11.86)$ & $75.3(16.69)$ & $68.7(12.26)^{\mathrm{a}}$ & $71.8(13.88)^{*}$ \\
\hline Height, mean (SD), cm & $168.5(9.87)$ & $168.5(9.43)$ & $166.1(11.24)$ & $166.2(10.16)$ & $167.1(10.08)$ \\
\hline BMI, mean (SD), $\mathrm{kg} / \mathrm{m}^{2}$ & $26.0(3.74)$ & $25.6(3.25)$ & $27.2(4.83)$ & $24.8(3.32)^{\mathrm{b}}$ & $25.6(3.84)^{* *}$ \\
\hline \multicolumn{6}{|l|}{ MMSE total score } \\
\hline Mean (SD) & $28.3(1.49)$ & $28.3(1.80)$ & $27.3(2.76)$ & $25.3(3.24)$ & $26.8(2.95)$ \\
\hline Median (range) & $29(24 ; 30)$ & $29(21 ; 30)$ & $28(19 ; 30)$ & $26(14 ; 30)^{\mathrm{c}}$ & $28(14 ; 30)^{* * *}$ \\
\hline \multicolumn{6}{|l|}{$A P O E$ \&4 carrier, $\mathrm{n}(\%)$} \\
\hline Yes & 0 & $17(51.5)$ & 0 & $58(54.7)$ & $75(30.5)$ \\
\hline Missing/unknown & $69(100)$ & $5(15.2)$ & $38(100)$ & $10(9.4)$ & $122(49.6)$ \\
\hline \multicolumn{6}{|l|}{$\begin{array}{l}\text { CDR global score, } \mathrm{n} \\
(\%)\end{array}$} \\
\hline 0 & $69(100)$ & $33(100)$ & 0 & 0 & $102(41.5)$ \\
\hline$\geq 0.5$ & 0 & 0 & $38(100)$ & $106(100)$ & $144(58.5)$ \\
\hline \multicolumn{6}{|l|}{ RBANS total score } \\
\hline Mean (SD) & $102.0(12.70)$ & $97.5(17.37)$ & $84.4(15.19)$ & $73.5(16.13)$ & $86.4(19.69)$ \\
\hline Median (range) & $102(67 ; 136)$ & $101(57 ; 135)$ & $87(51 ; 114)^{\mathrm{d}}$ & $74(47 ; 124)^{\mathrm{c}}$ & $87(47 ; 136)^{* * *}$ \\
\hline \multicolumn{6}{|l|}{ Biomarkers } \\
\hline \multicolumn{6}{|c|}{$A \beta 1-42$ (innotest), ng/L } \\
\hline Mean (SD) & $860.9(182.55)$ & $416.5(103.89)$ & $840.4(152.33)$ & $390.8(94.61)$ & $595.6(263.79)$ \\
\hline Median (range) & $860(600 ; 1580)$ & $395(244 ; 590)^{\mathrm{e}}$ & $815(616 ; 1320)$ & $\begin{array}{c}384.5(159 \\
586)^{\mathrm{e}}\end{array}$ & $\begin{array}{c}526.5(159 \\
1580)^{* * *}\end{array}$ \\
\hline$<600$ ng/L, n (\%) & 0 & $33(100)$ & 0 & $106(100)$ & $139(56.5)$ \\
\hline \multicolumn{6}{|l|}{ T-tau, ng/L } \\
\hline Mean (SD) & $345.2(135.65)$ & 427.9 (192.57) & $321.2(137.53)$ & $730.9(333.26)$ & $518.8(309.06)$ \\
\hline Median (range) & $324(152 ; 742)$ & $\begin{array}{c}404(118 \\
1050)^{\mathrm{f}}\end{array}$ & $300(100 ; 661)$ & $\begin{array}{c}644.5(161 \\
1780)^{\mathrm{g}}\end{array}$ & $\begin{array}{l}448(100 \\
1780)^{* * *}\end{array}$ \\
\hline$>350$ ng/L, n (\%) & $26(37.7)$ & $20(60.6)$ & $11(28.9)$ & $96(90.6)$ & $153(62.2)$ \\
\hline \multicolumn{6}{|l|}{ P-tau, ng/L } \\
\hline Mean (SD) & $53.4(18.73)$ & $62.2(21.89)$ & $48.9(8.43)$ & $90.0(33.51)$ & 69.7 (31.94) \\
\hline Median (range) & $50(25 ; 116)$ & $59(23 ; 128)^{\mathrm{f}}$ & $46(20 ; 103)$ & $86.5(29 ; 197)^{\mathrm{g}}$ & $64(20 ; 197)^{* * *}$ \\
\hline$>70$ ng/L, n (\%) & $13(18.8)$ & $12(36.4)$ & $4(10.5)$ & $76(71.7)$ & $105(42.7)$ \\
\hline
\end{tabular}

$\mathrm{A} \beta$, amyloid- $\beta$; AD, Alzheimer's disease; APOE, gene encoding for apolipoprotein E; BMI, body mass index; CDR, clinical dementia rating; MCI, mild cognitive impairment; MMSE, mini-mental state 
examination; P-tau, phospho tau; RBANS, repeatable battery for the assessment of neuropsychological status; SD, standard deviation; T-tau, total tau.

$* * *, * *, *$ indicates nominal p-value $<0.001,<0.01$, or $<0.05$, respectively, across groups.

a nominal p-value $<0.01$ vs Control; $<0.05$ vs MCI.

${ }^{\mathrm{b}}$ nominal p-value $<0.05$ vs Control; $<0.01$ vs MCI.

${ }^{c}$ nominal p-value $<0.001$ vs Control, vs Preclinical AD and vs MCI.

d nominal p-value $<0.001$ vs Control, vs Preclinical AD and vs Prodromal AD.

${ }^{\mathrm{e}}$ nominal p-value $<0.001$ vs Control and vs MCI.

${ }^{\mathrm{f}}$ nominal p-value $<0.05$ vs Control; $<0.01$ vs MCI and $<0.001$ vs Prodromal AD.

$\mathrm{g}$ nominal p-value $<0.001$ vs Control, vs Preclinical AD and vs MCI. 


\begin{tabular}{|c|c|c|c|c|c|}
\hline & $\begin{array}{c}\mathbf{A}-/ \mathrm{T}- \\
\mathbf{N}=70\end{array}$ & $\begin{array}{c}\mathbf{A}-/ \mathbf{T}+ \\
\mathbf{N}=\mathbf{3 7}\end{array}$ & $\begin{array}{c}\mathbf{A} \beta / \text { tau status } \\
\mathbf{A}+/ \mathbf{T}- \\
\mathbf{N}=\mathbf{2 3}\end{array}$ & $\begin{array}{l}\mathrm{A}+/ \mathrm{T}+ \\
\mathrm{N}=116\end{array}$ & $\begin{array}{c}\text { Total } \\
\mathrm{N}=246\end{array}$ \\
\hline \multicolumn{6}{|l|}{ Demographics } \\
\hline Women, n (\%) & $38(54.3)$ & $18(48.6)$ & $8(34.8)$ & $63(54.3)$ & $127(51.6)$ \\
\hline Age, mean (SD), years & $66.5(5.90)^{\mathrm{a}}$ & $69.6(5.85)$ & $68.6(5.12)$ & $69.6(7.01)$ & $68.6(6.49)^{*}$ \\
\hline \multicolumn{6}{|l|}{ Age group, $\mathrm{n}(\%)$} \\
\hline$<65$ & $23(32.9)$ & 7 (18.9) & $7(30.4)$ & $26(22.4)$ & $63(25.6)$ \\
\hline$\geq 65-<75$ & $42(60)$ & $24(64.9)$ & $13(56.5)$ & $56(48.3)$ & $135(54.9)$ \\
\hline$\geq 75$ & $5(7.1)$ & $6(16.2)$ & $3(13.0)$ & $34(29.3)$ & $48(19.5)$ \\
\hline \multicolumn{6}{|l|}{ Race, n (\%) } \\
\hline White & $69(98.6)$ & $37(100)$ & $22(95.7)$ & $114(98.3)$ & $242(98.4)$ \\
\hline $\begin{array}{l}\text { Black or African } \\
\text { American }\end{array}$ & $1(1.4)$ & 0 & 0 & 0 & $1(0.4)$ \\
\hline Other & 0 & 0 & $1(4.3)$ & $2(1.7)$ & $3(1.2)$ \\
\hline Weight, mean (SD), kg & $75.0(16.45)$ & $73.5(12.37)$ & $74.7(10.34)$ & $68.7(12.40)^{\mathrm{b}}$ & $71.8(13.88)^{* *}$ \\
\hline Height, mean (SD), cm & $166.7(10.56)$ & $169.4(9.99)$ & $171.2(9.91)$ & $165.8(9.82)$ & $167.1(10.08)$ \\
\hline BMI, mean (SD), $\mathrm{kg} / \mathrm{m}^{2}$ & $26.8(4.28)$ & $25.7(3.92)$ & $25.4(2.28)$ & $24.9(3.48)^{\mathrm{c}}$ & $25.6(3.84)^{*}$ \\
\hline \multicolumn{6}{|l|}{ MMSE total score } \\
\hline Mean (SD) & $28.0(1.93)$ & $27.8(2.37)$ & $28.0(2.18)$ & $25.6(3.27)$ & $26.8(2.95)$ \\
\hline Median (range) & $28(19 ; 30)$ & $28(21 ; 30)$ & $28(21 ; 30)$ & $26(14 ; 30)^{\mathrm{d}}$ & $28(14 ; 30)^{* * *}$ \\
\hline \multicolumn{6}{|l|}{$A P O E \& 4$ carrier, n (\%) } \\
\hline Yes & 0 & 0 & $11(47.8)$ & $64(55.2)$ & $75(30.5)$ \\
\hline No & 0 & 0 & $10(43.5)$ & $39(33.6)$ & $49(19.9)$ \\
\hline Missing/unknown & $70(100)$ & $37(100)$ & $2(8.7)$ & $13(11.2)$ & $122(49.6)$ \\
\hline \multicolumn{6}{|l|}{ CDR global score, n (\%) } \\
\hline 0 & $43(61.4)$ & $26(70.3)$ & $13(56.5)$ & $20(17.2)$ & $102(41.5)$ \\
\hline$\geq 0.5$ & $27(38.6)$ & $11(29.7)$ & $10(43.5)$ & $96(82.8)^{\mathrm{d}}$ & $144(58.5)^{* * *}$ \\
\hline \multicolumn{6}{|l|}{ RBANS total score } \\
\hline Mean (SD) & $94.8(14.61)$ & $97.5(18.41)$ & $93.6(18.78)$ & $76.4(18.17)$ & $86.4(19.69)$ \\
\hline Median (range) & $94.5(55 ; 125)$ & $99(51 ; 136)$ & $100(59 ; 124)$ & $76(47 ; 135)^{\mathrm{d}}$ & $\begin{array}{c}87(47 \\
136) * * *\end{array}$ \\
\hline \multicolumn{6}{|l|}{ Biomarkers } \\
\hline \multicolumn{6}{|l|}{$\mathrm{A} \beta \mathrm{1}-42$ (innotest), ng/L } \\
\hline Mean (SD) & $806.2(137.15)$ & $\begin{array}{c}943.3 \\
(195.94)\end{array}$ & $432.3(110.96)$ & $389.9(93.07)$ & $595.6(263.79)$ \\
\hline Median (range) & $\begin{array}{l}790(600 \\
1180)^{\mathrm{e}}\end{array}$ & $\begin{array}{l}903(607 ; \\
1580)^{\mathrm{f}}\end{array}$ & $421(259 ; 590)$ & $\begin{array}{l}381(159 ; \\
587)\end{array}$ & $\begin{array}{c}526.5(159 \\
1580)^{* * *}\end{array}$ \\
\hline$<600$ ng/L, n (\%) & 0 & 0 & $23(100)$ & $116(100)$ & $139(56.5)$ \\
\hline \multicolumn{6}{|l|}{ T-tau, ng/L } \\
\hline Mean (SD) & $257.1(62.11)$ & $\begin{array}{c}487.3 \\
(107.44)\end{array}$ & $257.5(69.10)$ & $\begin{array}{c}738.6 \\
(303.76)\end{array}$ & $518.8(309.06)$ \\
\hline Median (range) & $264(100 ; 350)$ & $\begin{array}{l}458(353 ; \\
742)^{\mathrm{f}}\end{array}$ & $262(118 ; 349)$ & $\begin{array}{l}637(354 ; \\
1780)^{\mathrm{g}}\end{array}$ & $\begin{array}{l}448(100 \\
1780)^{* * *}\end{array}$ \\
\hline$>350$ ng/L, n (\%) & 0 & $37(100)$ & 0 & $116(100)$ & $153(62.2)$ \\
\hline \multicolumn{6}{|l|}{ P-tau, ng/L } \\
\hline Mean (SD) & $41.5(9.68)$ & $71.5(15.53)$ & $41.8(9.29)$ & 91.7 (29.93) & 69.7 (31.94) \\
\hline Median (range) & $42.5(20 ; 62)$ & $69(46 ; 116)^{\mathrm{f}}$ & $41(23 ; 56)$ & $85(49 ; 197)^{\mathrm{g}}$ & $\begin{array}{c}64(20 \\
197)^{* * *}\end{array}$ \\
\hline$>70 \mathrm{ng} / \mathrm{L}, \mathrm{n}(\%)$ & 0 & $17(45.9)$ & 0 & $88(75.9)$ & $105(42.7)$ \\
\hline
\end{tabular}


$\mathrm{A} \beta$, amyloid- $\beta$; $A P O E$, gene encoding for E; BMI, body mass index; CDR, clinical dementia rating; MMSE, mini-mental state examination; P-tau, phospho tau; RBANS, repeatable battery for the assessment of neuropsychological status; SD, standard deviation; T-tau, total tau.

$* * *, * *, *$ indicates nominal p-value $<0.001,<0.01$, or $<0.05$, respectively, across groups.

${ }^{a}$ nominal p-value $<0.05$ vs $\mathrm{A}-/ \mathrm{T}+;<0.01$ vs $\mathrm{A}+/ \mathrm{T}+$.

${ }^{\mathrm{b}}$ nominal $\mathrm{p}$-value $<0.05$ vs $\mathrm{A}-/ \mathrm{T}+$ and vs $\mathrm{A}+/ \mathrm{T}-;<0.01$ vs $\mathrm{A}-/ \mathrm{T}-$.

${ }^{c}$ nominal $\mathrm{p}$-value $<0.01$ vs A-/T-.

${ }^{\mathrm{d}}$ nominal $\mathrm{p}$-value $<0.001$ vs $\mathrm{A}-/ \mathrm{T}-$, vs $\mathrm{A}-/ \mathrm{T}+$ and vs $\mathrm{A}+/ \mathrm{T}-$.

e nominal $\mathrm{p}$-value $<0.001$ vs $\mathrm{A}-/ \mathrm{T}+$, vs $\mathrm{A}+/ \mathrm{T}$ - and vs $\mathrm{A}+/ \mathrm{T}+$

${ }^{\mathrm{f}}$ nominal $\mathrm{p}$-value $<0.001$ vs $\mathrm{A}-/ \mathrm{T}-$, vs $\mathrm{A}+/ \mathrm{T}$ - and vs $\mathrm{A}+/ \mathrm{T}+$.

${ }^{\mathrm{g}}$ nominal $\mathrm{p}$-value $<0.001$ vs A-/T-, A-/T+ and vs A+/T- 
Table 2. Correlation of RBANS indexes vs T-tau and P-tau

\begin{tabular}{|c|c|c|c|c|c|c|}
\hline & \multicolumn{2}{|c|}{$\underset{\mathrm{N}=246}{\text { All }}$} & \multicolumn{2}{|c|}{$\begin{array}{c}\mathbf{A} \boldsymbol{\beta}- \\
\mathbf{N}=\mathbf{1 0 7}\end{array}$} & \multicolumn{2}{|c|}{$\begin{array}{c}\mathbf{A \beta}+ \\
\mathbf{N}=139\end{array}$} \\
\hline & T-tau & P-tau & T-tau & P-tau & T-tau & P-tau \\
\hline RBANS total score & $-0.434 * * *$ & $-0.389 * * *$ & 0.137 & 0.173 & $-0.451 * * *$ & $-0.421 * * *$ \\
\hline $\begin{array}{l}\text { RBANS sum of } \\
\text { index }\end{array}$ & $-0.433 * * *$ & $-0.391 * * *$ & 0.139 & 0.176 & $-0.449 * * *$ & $-0.422 * * *$ \\
\hline $\begin{array}{l}\text { RBANS delayed } \\
\text { memory }\end{array}$ & $-0.433 * * *$ & $-0.377 * * *$ & $0.236^{*}$ & $0.310 * *$ & $-0.431 * * *$ & $-0.406 * * *$ \\
\hline $\begin{array}{l}\text { RBANS immediate } \\
\text { memory }\end{array}$ & $-0.368 * * *$ & $-0.329 * * *$ & 0.086 & 0.109 & $-0.327 * * *$ & $-0.307 * * *$ \\
\hline $\begin{array}{l}\text { RBANS attention } \\
\text { Index }\end{array}$ & $-0.339 * * *$ & $-0.315^{* * *}$ & 0.119 & 0.120 & $-0.438 * * *$ & $-0.410 * * *$ \\
\hline $\begin{array}{l}\text { RBANS language } \\
\text { index }\end{array}$ & $-0.321 * * *$ & $-0.311 * * *$ & -0.052 & -0.049 & $-0.261 * *$ & $-0.275 * *$ \\
\hline $\begin{array}{l}\text { RBANS visuospatial } \\
\text { index }\end{array}$ & $-0.186^{* *}$ & $-0.165^{* *}$ & 0.063 & 0.069 & $-0.254 * *$ & $-0.223 * *$ \\
\hline
\end{tabular}

RBANS, repeatable battery for the assessment of neuropsychological status.

$* * *, * *, *$ indicates nominal p-value $<0.001,<0.01$, or $<0.05$, respectively. 


\section{Figures}

Figure 1. RBANS Total Scale Score

\section{$A: C D R / A \beta$ Status}

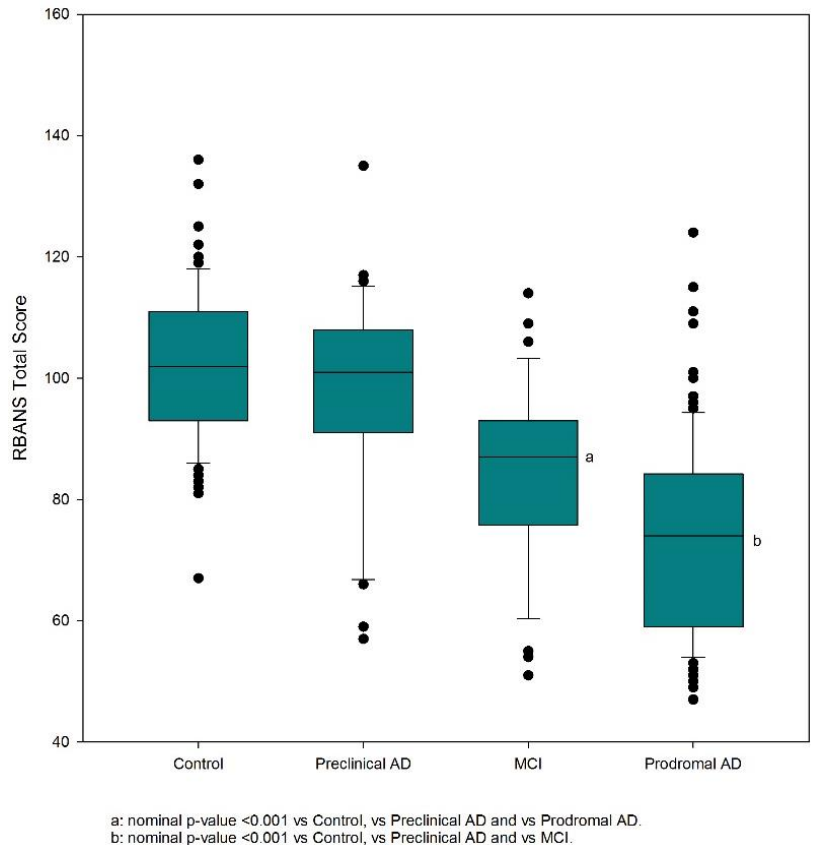

B. $A \beta\left(A^{+}\right.$or $\left.A^{-}\right) /$Tau $\left(T^{+}\right.$or $\left.T^{-}\right)$Status

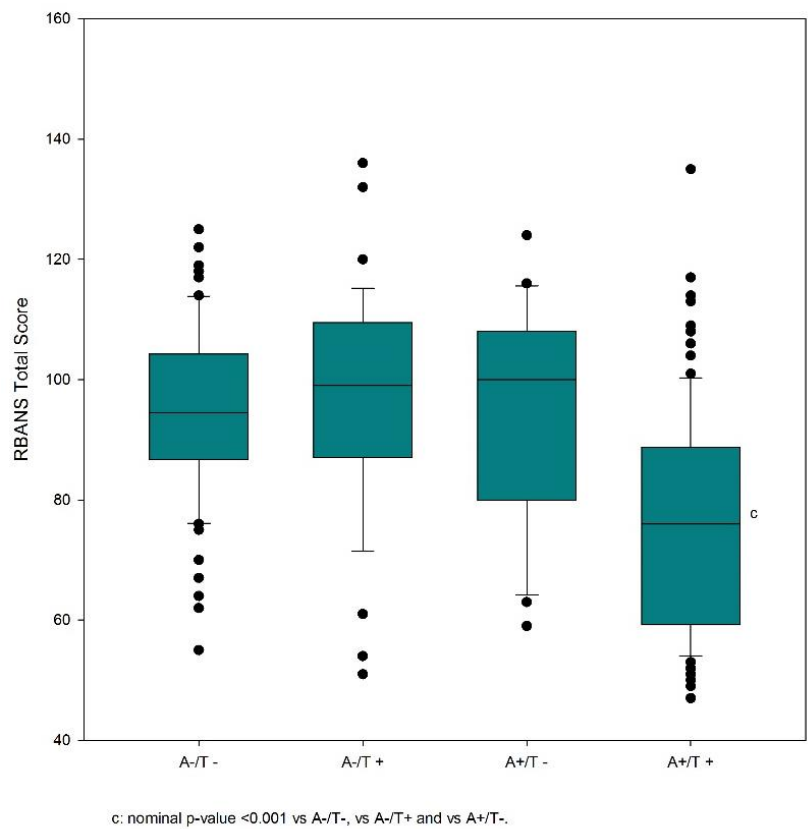

RBANS: repeatable battery for the assessment of neuropsychological status

Participants are considered $\mathrm{A} \beta+(\mathrm{A}+)$ if CSF $\mathrm{A} \beta_{1-42}<600 \mathrm{ng} / \mathrm{L}$ and Tau+ $(\mathrm{T}+)$ if CSF T-Tau $>350 \mathrm{ng} / \mathrm{L}$ or CSF p-Tau $181 \mathrm{P}>70 \mathrm{ng} / \mathrm{L}$. (A) Control (CDR 0;A $\beta-; n=69)$, pre-clinical AD (CDR 0; A $\beta+; n=33)$, MCI $(\mathrm{CDR} \geq 0.5 ; \mathrm{A} \beta-; \mathrm{n}=38)$, prodromal $\mathrm{AD}(\mathrm{CDR} \geq 0.5 ; \mathrm{A} \beta+; \mathrm{n}=106) ;(\mathrm{B}) \mathrm{A}-/ \mathrm{T}-(\mathrm{n}=70), \mathrm{A}-/ \mathrm{T}+(\mathrm{n}=37)$, $\mathrm{A}+/ \mathrm{T}-(\mathrm{n}=23), \mathrm{A}+/ \mathrm{T}+(\mathrm{n}=116)$. 
Figure 2. Correlation RBANS Total Scale Score and T-tau

\section{A: Overall Population}

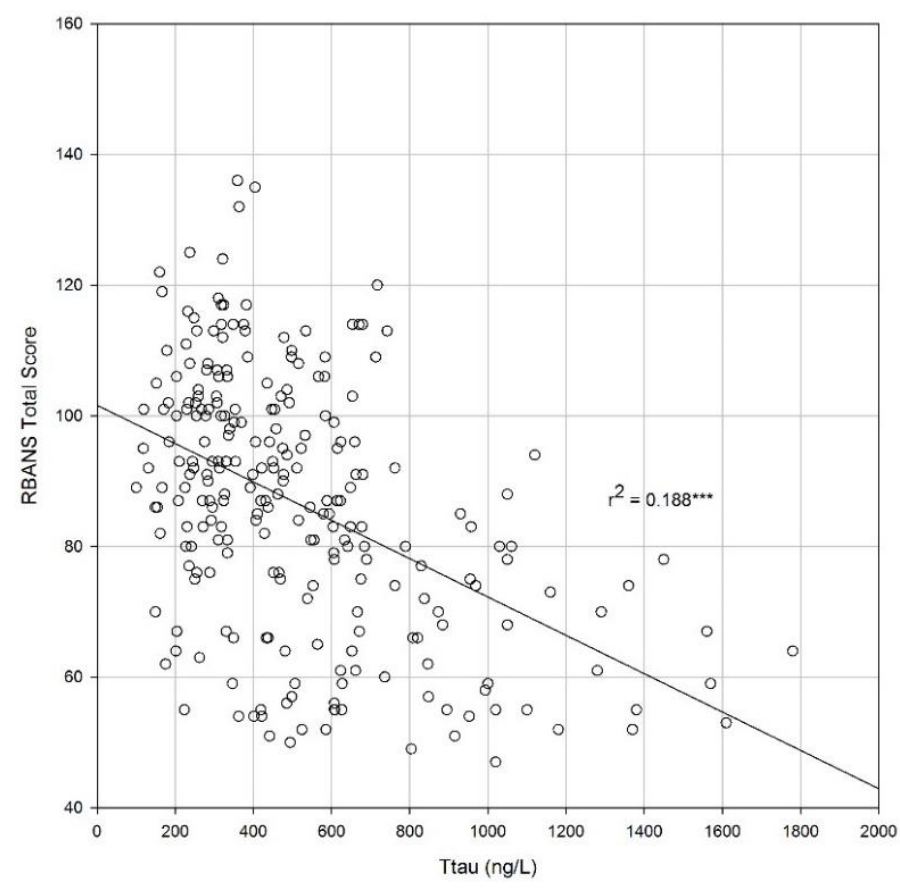

*** indicates nominal p-value $<0.001$

B. A $\beta$ Status

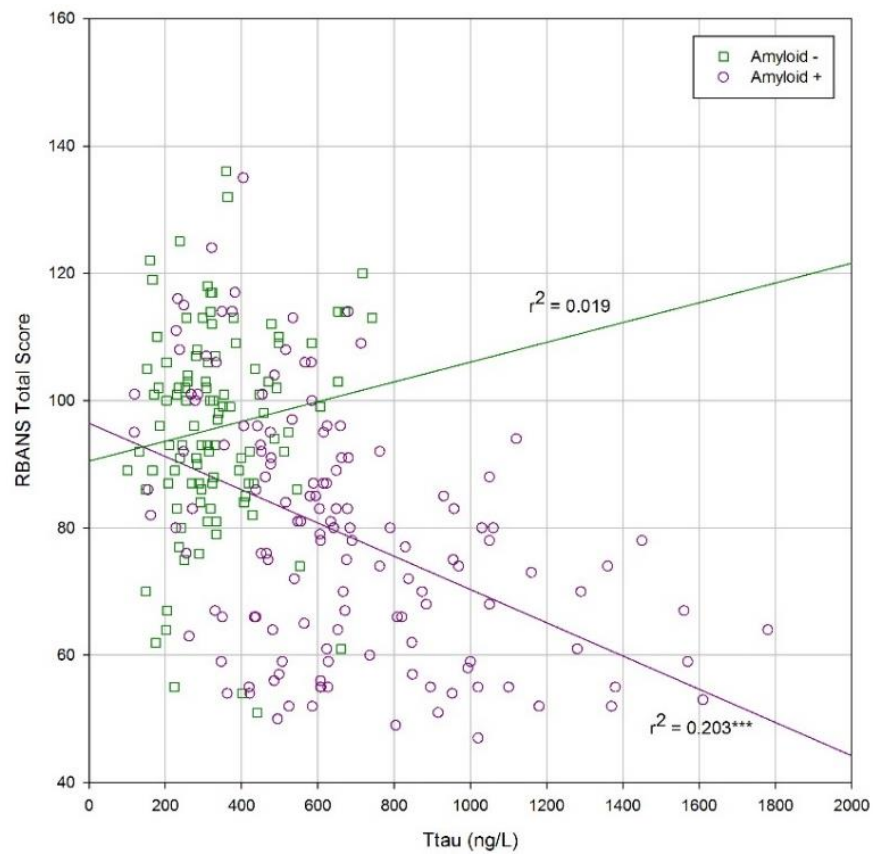

*** indicates nominal p-value $<0.001$

RBANS: repeatable battery for the assessment of neuropsychological status; Ttau: total tau A Spearman correlation coefficient was calculated to evaluate the possible correlation between RBANS Total Scale Score and t-tau for the overall population (A) and by $A \beta$ (amyloid) status (B). (A) $\mathrm{R}^{2}=0.188$, rho $=-0.434 ; \mathrm{p}<0.001 . n=246$; B. Amyloid $-: \mathrm{R}^{2}=0.019$, rho $=0.137, \mathrm{p}>0.05, \mathrm{n}=107$; Amyloid +: $\mathrm{R}^{2}=0.203$, rho $\left.=-0.451, \mathrm{p}<0.001, \mathrm{n}=139\right)$. 